\title{
MODOS DE NARRAR A NARRATIVA HOMOERÓTICA NA HISTÓRIA LITERÁRIA BRASILEIRA
}

Antonio de Pádua Dias da Silva (UEPB) Carlos Eduardo Albuquerque Fernandes (UFRPE)

Resumo: O presente artigo discute a maneira como quatro compêndios de história da literatura brasileira registram narrativas de temática homoerótica, bem como as estratégias discursivas para silenciar o tema homoerótico centralizado em narrativas dessa literatura ou mesmo negativizá-lo, optando-se por uma visão excludente e discriminatória. Palavras-Chave: Literatura homoerótica, Autores, Discursos, Exclusão, Discriminação.

Resumen: En este artículo se discute la forma con la cual cuatro compendios de historia de la literatura brasileña tratan las narrativas con temática homoerótica, como también las estrategias discursivas para acallar o negativizar el tema homoerótico cuando éste es el eje de dichas narraciones, optando por una visión excluyente y discriminatoria. Palabras clave: Literatura homoerótica, Autores, Discursos, Exclusión, Discriminación.

As várias discussões em torno dos cânones literários parecem não ter esgotado os antigos problemas contra os quais pesquisadores e críticos em geral se posicionaram em vários estudos que proliferaram nas décadas de 1980 e 1990¹, sobretudo quando as questões levantadas diziam respeito às escritas de autoria feminina (GOTLIB, 2003). Estas, por serem desconsideradas pela crítica legitimadora do cânone,

1 As obras de Flávio René Kothe - O cânone colonial (1997), O cânone imperial (2000), O cânone republicano I (2003) e O cânone republicano II (2004) constituem importante documento de revisão do discurso canônico dito masculino, "bairrista" e cristão. 
alcançaram projeções em vários cursos de pós-graduação no País, o que possibilitou, por parte da crítica especializada e dos leitores, outras abordagens dos textos literários que incluíam autoras e suas obras. Um dos objetivos desses estudos foi o de democratizar o acesso à leitura, à produção, à crítica desses textos, como também incluir as escritas que margeavam os autores e obras do cânone.

Em meio a essas proposições discursivas, uma literatura que emerge com vigor a partir dos anos 1990, na cultura brasileira, sem nenhuma vinculação direta com os escritores que já escreviam na mesma base temática e que não se ressentiam de terem seus nomes e suas obras circulando nos meios acadêmicos, nas mídias, é a chamada literatura homoerótica², aflorando em determinados contextos e recebendo nomes às vezes resistentes por parte de leitores e formadores de opinião (professores de literatura, críticos literários, editoras). A baliza temporal é apenas o mote para o boom, pois esta literatura, vale salientar, desde antes mesmo do século $X X$, em menor ocorrência, já figurava nas páginas de nossa cultura beletrista.

Em tempos de problematização de discursos, parece necessária uma revisão da literatura brasileira no que diz

2 Apesar de polêmica, estamos empregando essa expressão e outras - literatura gay, lésbica, homoerótica, homoafetiva - como forma de agrupar textos literários que centralizam as relações íntimas, afetivas ou o desejo entre pessoas do mesmo sexo. Sobre caracterização da literatura homoerótica, ver a discussão promovida por nós em outro momento (Silva, 2010). 
respeito às obras e autores da literatura homoerótica, sobretudo quanto aos modos de narrá-los em textos cujos discursos tornam visíveis as marcas de exclusão, de preconceito, de leituras equivocadas. Uma vez que estamos partindo de uma perspectiva que não se submete ao discurso de vitimização, muito menos de quem quer sobrepor uma visada literária à outra, torna-se imperativo uma crítica ao discurso produzido e repetido em gestos de poder que circulam nos meios onde leitores são influenciados pelos formadores de opinião.

A Literatura Brasileira tem passado por vários crivos, sobretudo aqueles que procuram explorar, na produção da ficção nacional, aspectos voltados para as grandes e polêmicas discussões surgidas na contemporaneidade. Ler um compêndio de história da literatura brasileira e encontrar nele uma visão não correspondente ao que se entende hoje como literatura soa, no mínimo, estranho.

Quando pensamos como Beatriz Resende (2008), que constata ser marca da literatura contemporânea a pluralidade de gêneros literários (não mais os centrados nos três segmentos clássicos), de autores (oriundos de várias espacialidades sociais), de temas (conflitos pessoais, desejos, denúncia, crença), de compartimentos (literatura 
de autoria feminina, literatura gay), torna-se difícil ler um manual de história da literatura brasileira e não encontrar nele, como marca indelével, um registro invisibilizador e discriminatório, equívocos quanto aos modos de historiadores narrarem os autores, as obras e os temas que cerceiam as obras comentadas.

Nesse sentido, o objetivo deste artigo é percorrer quatro compêndios ${ }^{3}$ historiográficos da literatura brasileira, a saber, A literatura no Brasil (2004), de Afrânio Coutinho, História Concisa da Literatura Brasileira (2006), de Alfredo Bosi, A Literatura Brasileira através dos textos (2007), de Massaud Moisés e História da Literatura Brasileira (1997), de Luciana Stegagno Picchio, evidenciando os modos de dizer da e sobre a literatura que tematiza o desejo gay.

O critério de escolha desses compêndios foi baseado no fato de eles serem bastante difundidos nos cursos de Letras, também porque possuem um alcance temporal que se estende do Quinhentismo às tendências contemporâneas (geralmente tecem comentários acerca de obras datadas até o início da década de 1980), o que não ocorre, por exemplo, com obras como Formação da Literatura Brasileira (2006), de Antonio

3 Os compêndios historiagráficos da literatura brasileira materializam o discurso, o jogo, a dinâmica, os modos de ver e de interpretar autores e obras que ficam registrados, a partir de um dado ou de dados valores, constituindo, então, autor e obras canônicas, segundo esse modo de entender da crítica e da cultura em que se insere. 
Candido, A literatura no Brasil (1995), de Luiz Roncari e História da Literatura Brasileira (1998), de José Veríssimo, cujo alcance temporal limita-se à literatura produzida no século XIX.

\section{MODOS DE NARRAR AUTORES, OBRAS E PERSONAGENS DA LITERATURA HOMOERÓTICA NO CÂNONE}

Existe uma vagueza semântica em relação ao conceito de cânone, segundo Cunha (2006). As formas de ele ser descrito, caracterizado, conceituado alicerçam-se em ideias que nos soam como se ele fosse invisível, impalpável. Esta discussão parece, muitas vezes, recair numa abstração de manifestação do poder, embora detentora do controle sobre o corpus oficial da literatura brasileira. O principal critério de inclusão de uma obra no cânone, geralmente alegado por seus defensores, é o fator estético, sobre o qual Cunha (2006) argumenta ser bastante relativista após tantas transformações culturais e literárias e, por isso, insuficiente para determinar a inclusão ou exclusão de obras e autores nos compêndios de literatura.

Sobre este tópico Kothe (1997), de forma bastante radical, afirma que o valor estético é, na verdade, o que menos importa na seleção de obras canônicas no Brasil, porque os fatores político e ideológico são decisivos para definir ou não a entrada de um autor e de uma obra no cânone: "O cânone 
é formado por textos elevados à categoria de discurso, [...] o fundamento de sua poética é, no entanto, política" (p. 108). O radicalismo do crítico consiste no fato de nivelar todos os autores e obras do registro canônico brasileiro como constando na memória cultural sem valor literário requerido.

Podemos sintetizar que o cânone literário é um sistema simbólico e material de valorização exacerbada de obras literárias e documentais que se concretiza através das listas de obras que são divulgadas para o público (segundo Kothe (1997), nem sempre são literárias as obras escolhidas como canônicas). Canônicos são os textos e autores que constam na grande maioria dos livros de historiografia literária estudados nas graduações e pós-graduações na área de Letras; são os textos que constam nos livros didáticos do Ensino Fundamental e Médio. Sobre os autores dessas obras, publicam-se a maior quantidade de antologias, de traduções e de estudos críticos que solidifiquem sua hegemonia.

Nesse sentido, subjaz ao discurso do cânone uma relação de poder na qual, hierarquicamente, autores e obras são interpretados como superiores aos que foram omitidos ou excluídos da "lista". Daí percebermos, com Crystófol y Sel (2008), que tanto a censura como a supervalorização de autores e obras, em detrimento de outros, é uma prática comum de 
quem se coloca como construtor e mantenedor do cânone.

Geralmente, os manuais de história da literatura - registros do discurso e do gesto semântico que listam os autores e as obras canônicas mantêm uma mesma quantidade de obras, de seleção de autores, mesma atribuição valorativa aos textos, formando uma rede através da qual se reforça, segundo Kothe (1997), a ideia do cânone literário brasileiro como um discurso autoritário que não dialoga com a possibilidade de revisão e consequente alteração, mantendo estabilizados os discursos de sustentação de determinadas ideologias que marginalizaram textos, temas e autores da Literatura Brasileira.

Na contramão desse argumento, analisamos os referidos manuais no intuito de percebermos os modos de narrar dos historiadores quanto às questões homoeróticas em suas relações com os autores e com as obras, quando evidenciadas, de algum modo, no tecido discursivo.

Um primeiro objetivo traçado foi o de verificar se há menção da temática homoerótica em obras da Literatura Brasileira e, depois, que tipos de comentários são tecidos sobre o autor, o tema ou sobre as personagens homoeróticas inseridas nas narrativas ${ }^{4}$. Os modos de narrar desses historiadores tornam

\footnotetext{
4 Apesar da temática homoerótica estar presentes nos vários gêneros literários, por exigência dos registros historiográficos sobre os quais nos debruçamos, trataremos apenas das narrativas, pois os historiadores, quando procuram revelar um autor ou uma obra de temática homo, aludem geralmente às narrativas.
} 
visíveis, às vezes escandalosos, o sentimento nutrido pelo valor atribuído ao texto ou ao autor que tornou central, em sua(s) obra(s), questões homoeróticas.

É comum não encontrarmos menções a obras de temática homoerótica nesses compêndios ou, quando a obra é mencionada, há a omissão do tema, como ocorre com Coutinho (2004) ao comentar um dos romances mais valorizados na Literatura Brasileira, Grande sertão: veredas, de Guimarães Rosa. No texto ficcional, dentre tantos conflitos abordados, está presente, do início ao fim da obra, o desejo homoerótico (não concretizado) entre Riobaldo (protagonista) e Reinaldo/Diadorim (amigo e parceiro de seu bando).

Coutinho (2004) dá ênfase à inovação linguística rosiana e ao mito do Fausto (encontro/pacto de Riobaldo com o Diabo) que também é aspecto muito forte no romance, tangenciado pelo conflito amoroso com Diadorim. O mesmo faz Alfredo Bosi (2006) ao mencionar que "Riobaldo é um homem que busca, no vaivém de suas memórias e reflexões, negar a existência real do demônio [...]" (p. 432). Massaud Moisés (2007) escreve um pequeno resumo da obra no qual sugere o sentimento de Riobaldo por Diadorim:

Em monólogo, Riobaldo conta sua odisséia de jagunço, empenhado tão a 
fundo na vingança do grande Joca Ramiro, que estabelece pacto com o Diabo. Além do sentimento de fidelidade, impele-o uma estranha afeição por Diadorim, companheiro de luta. (MOISÉS, 2007, p. 567, itálicos nossos)

É curioso perceber o modo como o historiador narra a "estranha afeição por Diadorim", permitindo entender o desejo homoafetivo como um tabu, fato que parece impedilo de se expressar abertamente sobre esse tema na obra, algo que não pode ser dito, reiterando o aforismo de Oscar Wilde sobre o "amor que não ousa dizer o nome", logo, distante da interpretação do olhar canônico e, talvez, por isso, a escolha do termo "estranho" para definir e valorar o sentimento de Riobaldo. Esse é o único momento que Moisés (2007) menciona essa aproximação entre as personagens, numa espécie de amnésia intencional que exclui de sua visão todo o conflito vivido pelo jagunço Riobaldo que se declara a todo o instante afeiçoado afetivamente por Reinaldo, outro jagunço do bando ${ }^{5}$. Luciana Stegagno Picchio (1997) também faz referência ao mesmo sentimento, quando resume o romance que, para ela, é a maior obra de Guimarães Rosa:

Riobaldo narra em blocos diferentes, cada um com seu sinal e sentimento, a aventura de sua vida, o pacto com

5 A discussão sobre o travestimento de Diadorim em Reinaldo não é objetivo nosso neste artigo, pois o assunto exige outro texto. 
o diabo (Riobaldo-Fausto), o sertão percorrido por bandos inimigos sedentos de vingança, a camaradagem ambiguamente afetuosa com Diadorim, o misterioso rapaz de olhos verdes: que se revela só no final, em sua morte, donzela. (PICCHIO, 1997, p. 609, itálicos nossos)

Picchio (1997), de forma semelhante a Moisés (2007), usa um modo não direto, sobretudo impreciso, para narrar o afeto entre as personagens em tela; na expressão "camaradagem ambiguamente afetuosa com Diadorim" infere-se uma espécie de insinuação, no entanto, esta forma sinuosa de narrar omite o real conflito em que se insere o sujeito protagonista do romance: o do desejo homoerótico, o da masculinidade posta em xeque a partir de um sentimento afetivo e do não querer admitir o desejo por um seu igual. Os demais historiadores que não optaram por um resumo da obra, não mencionam a personagem Diadorim e preferiram tratar, de forma generalizada, da mitopoética e da inovação linguística em Guimarães Rosa, deixando de narrar, a partir do expediente da ficção, as relações afetivas entre sujeitos do mesmo sexo, isto é, castrando as personagens, invisibilizando as imagens construídas, tornando o discurso sobre a obra com um foco que caminha apenas em via de mão única, a do discurso hegemônico e higiênico. 
Além desta omissão, outro modo de narrar recorrente entre os historiadores citados é o fato da temática (homoerótica) das obras ser concebida negativamente, como ocorre com a narrativa Bom-Crioulo, de Adolfo Caminha, considerado o segundo romance em nossas letras a narrar o erotismo entre pessoas do mesmo sexo. Até os dias atuais o tema da obra, de forma genérica, parece sobreviver sob a égide de uma recepção negativa, sobretudo em determinados setores tradicionais da crítica.

Alfredo Bosi (2006), ao se referir ao autor, afirma que ele possuía gosto por temas "escabrosos" (p. 193), termo que admite o significado de "indecente" (Cf. Houaiss; Villar, 2004); em outro trecho, o historiador evidencia que "O Bom Crioulo [...] resiste ainda hoje a uma leitura crítica que descarte os vezos da escola e saiba apreciar a construção de um tipo, o mulato Amaro, coerente na sua passionalidade que o move, pelos meandros do sadomasoquismo, à perversão e ao crime." (BOSI, 2006, p. 194, itálicos nossos). As duas palavras em destaque (sadomasoquismo, perversão), a nosso ver, foram usadas de forma aleatória, pois não nos parece, no caso da primeira, que a obra permita uma leitura sob este aspecto, e a segunda (pervesão, segundo Houaiss e Villar (2004), é "devassidão, depravação, indecência"), nessa mesma linha 
de raciocínio, deixa claro que o termo carrega consigo, semanticamente, uma apreciação moralista em relação ao tema homoafetivo na obra e, considerando-se que se trata de uma visada crítica, pode-se notar o quanto este tipo de concepção canônica, ainda presente no discurso de alguns críticos da geração dos hostoriadores aqui em estudo, lança uma visão não afirmativa e discriminatória quanto ao tema das subjetividades homoeróticas representadas na ficção literária brasileira.

Em Coutinho (2004), o romance gay mais conhecido e antigo do Brasil recebe a seguinte descrição:

Três anos depois do aparecimento de $A$ normalista, Adolfo Caminha publica Bom Crioulo. E deixa neste novo romance o melhor testemunho de sua grande vocação de romancista. A revolta da província é substituída em Bom Crioulo por uma audácia mais firme e ampla, que não mais se restringe aos estreitos horizontes da cidade pequena: tomando como tema um caso de homossexualidade, vai aos limites da transposição literária dessa degenerescência, com um requinte de minúcias que constrange e repugna. (COUTINHO, 2004, p. 87, itálicos nossos)

O fato da obra agregar-se culturalmente à "degenerescência", que "constrange e repugna", talvez seja 
uma questão de leitura bastante subjetiva e discriminatória de Coutinho (2004), porque construída, infere-se, sob visões pessoais. Todavia, utilizar esses termos numa escrita historiográfica que serve de baliza a leitores que porventura a consultem para obter informações sobre a literatura no Brasil está longe de ser entendida como uma crítica literária séria, como um pensamento ou ideia capaz de ser levada adiante por leitores que convivem com a diversidade sexual, com as diferenças de gênero, com as políticas em favor de minorias gays, lésbicas, trans (transgênero, travesti, transex, transhomem, transmulher, translésbica e outras).

É de impressionar o uso dos termos para se referir ao tema norteador da obra e à indicação de uma possível recepção, fato que, na pena do crítico, constrangeria, provavelmente, o leitor que se deparasse com o romance em questão. Poderíamos até entender o modo de narrar do historiador e crítico, se ele tornasse claro ao leitor que está pontuando a obra da forma que escolheu por razões de ordem pessoal e que o "constrangimento" só seria materializado, de fato, entre leitores que fossem adeptos do mesmo tipo de ideologia, pensamento ou valor que ele defende. Como isso não vem à tona, a escrita historiográfica é lesada, neste sentido, quanto ao seu valor de verdade, à razão da análise da obra, à seriedade de uma crítica especializada. 
O que se percebe, a partir dessa apreciação de Coutinho (2004), é uma espécie de censura que, como já afirmamos, é atitude comum na constituição do cânone (Crystófol y Sel, 2008). Nos textos dos demais historiadores investigados, o que se lê é a reiterada omissão do aspecto homoerótico que é visivelmente protagonizado na narrativa romanesca de Adolfo Caminha: Picchio (1997) sequer menciona Bom Crioulo entre as obras de Adolfo Caminha (obstaculiza a autoria pela invisibilização do texto), já Moisés (2007) dá ênfase a outro aspecto da obra (tornando-a menor, ao invisibilizar o tema homoerótico): afirma que o romance "focaliza o problema da escravidão" (p. 270), deixando de lado o que se relaciona ao homoerótico, ao desejo gay.

De acordo com o pensamento de Thomé (2009), um dos maiores clássicos da literatura brasileira do século XX é o romance Crônica da casa assassinada, de Lúcio Cardoso, publicado em 1959 e em cuja estrutura narrativa um dos núcleos temáticos é protagonizado pela travesti Timóteo, que transgride a norma dos papéis de gênero, vive trancado em um quarto, vestido de mulher, fato que desencadeia todo um desconforto nos demais sujeitos ficcionais do romance cardosiano.

Ainda segundo o mesmo crítico (2009, p. 189), essa 
personagem "subverte o cânone", modifica a visão das personagens homoeróticas na literatura. Talvez por esse motivo, nem essa personagem travesti, nem tampouco o viés homoerótico do romance de Lúcio Cardoso emergem como possibilidade de leitura nos compêndios historiográficos. O autor sequer é mencionado nas obras de Moisés (2007) e Picchio (1997) e, apesar de exaltado por Coutinho (2004) e Bosi (2006) quanto ao modo introspectivo, intimista de abordar os conflitos das personagens, sobretudo Timóteo, o caráter subversivo quanto às questões de gênero e de sexualidades de uma de suas principais personagens não é citado. A indiferença, nestes termos, parece constituir, mais uma vez, uma profunda censura que silencia, torna invisível a obra em seu aspecto temático e quanto ao seu valor estético observado de forma mais ampla.

O discurso canônico desvia um tema central, e importante, da obra para defender uma crítica que cala aquilo que é provocador do ponto de vista da construção do enredo, da performance da personagem, dos valores agregados à cultura representada.

Depois da obra de Lúcio Cardoso, a única obra que possui a temática homoerótica com uma travesti como protagonista (estudada pela crítica especializada) e que é mencionada nos 
compêndios de história da Literatura Brasileira, vem a ser Stella Manhattan, de Silviano Santiago. O romance é citado apenas por Picchio (1997), dentre os demais historiadores consultados, o que reitera o modus operandi da construção do discurso canônico, segundo leitura nossa em consonância com outros críticos, de que questões de gosto pessoal, de identificação com o autor ou a obra são critérios postos em primeiro plano para narrar as obras e os autores canonizados:

um "profissional da literatura" como Silviano Santiago (n. 1936) que, essencialmente crítico e ensaísta, se afirma também como contista e romancista: ([...] Stella Manhattan, 1985, em que, numa Nova York cosmopolita, as relações sexuais entre minorias étnicas são vistas através dos olhos de um brasileiro homossexual; e Keith Jarrett no Blue Note, improvisos de Jazz, 1996, quando mais de dez anos depois as temáticas da sexualidade gay e da vida no exterior reaparecem, dessa vez na forma de cinco contos). (PICCHIO, 1997, p. 645 , itálicos da autora)

Como se vê, o modo de narrar autor e obra é orientado por uma economia de ideia, atendo-se ao gesto de apreciar a pessoa, tornando secundária a discussão em torno das "temáticas da sexualidade gay". Mesmo quando a autora registra as produções de Caio Fernando Abreu, autor 
deveras conhecido pela abordagem do tema homoerótico em suas narrativas, seu modo de narrar o autor e as obras se distancia das questões centrais em que estão envolvidas as personagens de Caio Fernando Abreu:

Encontraremos também um ficcionista refinado e discreto como Caio Fernando Abreu (1948-1996) que, na sua breve vida de escritor marginalizado, nos deu um reduzido ciclo de obras-primas "urbanas" com personagens isoladas no mundo e prisioneiras delas mesmas. Contos e romances de formação, como ritos de passagem, eles possuem uma dimensão surrealista em que mais evidente se torna o conflito entre indivíduo e sociedade (Morangos mofados, 1981; Quem tem medo de Dulce Veiga ${ }^{6}$ ?, 1990; e póstumo, Bem longe de Marieband, 1996). (PICCHIO, 1997, p. 636, itálicos da autora).

Nestes trechos, percebemos que a autora menciona, de forma en passant, o caráter homoerótico nas obras de Silviano Santiago; o que falta ao narrar Caio Fernando Abreu, embora ela cite Morangos mofados e Bem longe de Marieband, obras de temática gay, é a atitude mais crítica e racional quanto ao tratamento a ser dado a autores e obras que se tornam autores, na perspectiva foucaultiana (2009), pelas ideias desenvolvidas e pelas quais saem do anonimato.

6 Destaque-se o equívoco da autora ao mencionar o título da obra de Abreu que, na verdade, intitula-se Onde andará Dulce Veiga?. 
No caso de Caio Fernando Abreu, marcadamente em suas narrativas estão os conflitos, os desejos, as tensões das subjetividades homoeróticas constantemente rasurando os lugares da cultura, as fronteiras de gênero e de sexualidades. Esta leitura, apesar de os manuais de história da literatura serem contemporâneos de autores como Guimarães Rosa, Silviano Santiago (ainda vivo) e Caio Fernando Abreu, não é contemplada por parte da crítica especializada do momento (ainda hoje) que opta por silenciar este aspecto, talvez, como na visão de Coutinho (2004), constrangedor. Isto demonstra que a obra da brasilianista Luciana Stegagno Picchio, assim como os demais, possui limitações histórico-interpretativas. Nos outros manuais consultados, nem Caio Fernando Abreu, nem Silviano Santiago são citados como autores.

De todos os manuais consultados, o que mais diverge quanto ao modo de abordagem, quando comparado aos demais e possui maior alcance temporal no aspecto "descrição de obras" (chega a descrever textos da década de 1990), é o de Picchio (1997); ainda assim, não registra os romances de Cassandra Rios, que tiveram grande repercussão desde a década de 1940 - com a publicação do seu primeiro livro A volúpia do pecado, lançado em 1948 - até as décadas de 1970 e 1980 com seus romances mais conhecidos. Nestes, 
a construção sem pudores de situações afetivas e sexuais entre personagens hetero ou homoeroticamente orientadas provocou o sucesso de público, quando chegou a vender mais de cem mil exemplares em um ano e, por outro lado, a censura do regime militar proibiu 36 das quase cinquenta obras da escritora (Cf. Almeida, 2014).

Cassandra Rios, hoje maior ícone da literatura homoerótica feminina, também não é mencionada nos demais compêndios que analisamos, sendo excluída por uma crítica especializada que torna desimportante o impacto de venda das obras dela, bem como a construção de um público leitor, o aquecimento de uma parte do mercado editorial quase sempre restrita a uma tiragem e vendagem de poucos exemplares. Por que Cassandra Rios não foi discutida como uma autora de Best Seller à brasileira?

Em outro momento discutimos a necessidade de atualização da história literária no Brasil quanto aos aspectos aqui em discussão (FERNANDES, 2009). No entanto, também compreendemos as limitações epistemológicas de abarcar tudo o que foi silenciado no cânone brasileiro, ao longo do tempo, cabendo, portanto, à crítica especializada (mas não imbuída de preconceito e discriminação) resgatar, discutir e tornar visível obras específicas que problematizam questões de minorias culturais, como tem ocorrido com a 
literatura feminina, com a literatura negra e com a literatura homoerótica. Neste último caso, nosso esforço se caracteriza por uma contribuição quanto aos modos de ver e de narrar dos historiadores da literatura brasileira, sobretudo àqueles que se posicionam contrários à manifestação e efetivação da literatura de temática homoerótica, cabendo, por extensão, um resgate específico de obras de temática homoerótica, que foram invisibilizadas no cânone pela crítica canonizante.

\section{CONSIDERAÇÕES FINAIS}

A revisão aqui proposta dos registros de narrativas homoeróticas pelos compêndios de história da literatura brasileira só produzirá algum impacto no leitor, se as considerações sobre a literatura brasileira de temática homoerótica forem levadas a sério, como devem ser; se as obras forem lidas por uma crítica especializada que, ao invés de estabelecer juízos de valor fundados no tão somente gosto pessoal, perceba os rumos da literatura brasileira das três últimas décadas e interprete a produção ficcional deste período e de momentos anteriores na esteira do que pensa Josefina Ludmer (2010), quando lançou a ideia de "literaturas pós-autônomas", como aquela produção distante de uma estruturação das obras canônicas e tradicionais, porque rompe com a linearidade das ações, é protagonizada por 
sujeitos que falam de si e por si numa tentativa de se deixar ver, aderindo a um modo de dizer que borra os limites entre realidade e ficção, imaginação e experiência de vida.

É bem verdade que a literatura de temática homoerótica não tem sido produzida no Brasil apenas nas duas últimas décadas, mas o pensamento modernista, lá da Semana de 22 , tem reverberado em vários momentos, levando-nos a defender que o conceito de literatura, de crítica literária, que o pensamento construído em torno das artes e da literatura sofreram alterações ao longo de todo o século XX, apesar de a literatura de temática homoerótica ter sido invisibilizada, silenciada ou guardada como um segredo.

Beatriz Resende (2008) ao falar da literatura do presente aponta para as dimensões do urbano, das cidades grandes que propiciaram a construção e reformulação de discursos a ponto de compartimentos literários como literatura de autoria feminina e literatura gay serem possíveis em nossa cultura como modalidades escritas dessa arte, sem o ranço do preconceito e da discriminação.

A discussão em torno das representações de autores e obras da literatura homoerótica nos compêndios da Literatura Brasileira não é uma fala que se ressente da inclusão de obras no cânone literário, mas uma advertência aos leitores 
no sentido de que percebam, como diz Kothe (1997), os gestos semânticos de poder que tornam autores e obras "ventríloquos" da literatura, um repetindo o outro e, neste repetir, de acordo com a ideologia do momento (que parece ser a mesma, apesar do tempo transcorrido entre as gerações), alcançam lugares na memória nacional.

Os autores e obras que se distanciam do "ventriloquismo" alardeado pela crítica especializada e, tantas vezes, apática à discussão dos temas da homocultura, das subjetividades não normatizadas, são silenciados, deixados de lado, julgados com o preconceito e a ideia do não pertencimento, apesar de toda uma gama de leitores dos textos produzidos (de alguns, a exemplo de Caio Fernando Abreu, Silviano Santiago, João Gilberto Noll, Bernardo Carvalho, Cassandra Rios) e de críticas feitas a outros que sequer são mencionados nas páginas dessa história (a exemplo de Luís Capucho, João Silvério Trevisan, Aguinaldo Silva, Glauco Matoso).

Percebemos que os manuais de história da Literatura Brasileira consultados, quando fazem referência aos textos de temática homoerótica, em alguns casos omitem a apresentação desta temática mesmo quando ela é aspecto central na obra e, assim, acabam, nesses momentos, cometendo desvios interpretativos ao tentar direcionar a descrição ou narração 
do texto para um tema que não é central, mas tangente. Nesse sentido, as relações possíveis entre o cânone literário e a literatura homoerótica no Brasil têm sido, na maioria das vezes, conflituosas, quando não impossíveis.

Todavia, os modos de ver as literaturas hoje devem servir de lição aos que ainda se prendem a purismos temáticos, a somente estruturas canônicas da literatura: as literaturas marginais - como diz Férrez (2005) - estão se mostrando, encontrando seus leitores e críticos, saindo do anonimato, falando de si e por si. Logo, é preciso investir em novas leituras, sobretudo aquelas que se impregnam das subjetividades que estão na agenda contemporânea das culturas.

\section{REFERÊNCIAS}

ALMEIDA, Kyara Vieira de. Onde estão as respostas para as minhas perguntas?: Cassandra Rios - a construção do nome e a vida enquanto tragédia de folhetim (1955-2001). Tese (doutorado), Recife, Programa de Pós-Graduação em História, 207pp, 2014.

BARCELLOS, José Carlos. Literatura e homoerotismo em questão. São Paulo: Dialogarts, 2006.

BOSI, Alfredo. História concisa da literatura brasileira. 43ed. São Paulo: Cultrix, 2006.

CANDIDO, Antonio. Formação da literatura brasileira - momentos decisivos. 11ed. Rio de Janeiro: Ouro sobre azul, 2006.

COUTINHO, Afrânio. A literatura no Brasil. São Paulo: Global, 2004.

CRYSTÓFOL Y SEL, María Cruz. "Canon y censura em los estúdios de tradución literaria: algunos conceptos y pautas metodológicas para 
La investigación". In.: Trans - revista de traductología. Universidad de Malaga, p. 189-210, n.12. Recuperado em 21 de agosto de 2013, de: http://www.trans.uma.es/pdf/Trans_12/t12_189-210_MCCristofol.pdf. CUNHA, Helena Parente. Cânone: dúvidas e ambigüidades. In.: Scripta. v.10 n.16. Belo Horizonte, pp. 241-249, 2006.

FERNANDES, Carlos Eduardo Albuquerque. Reflexões sobre a narrativa brasileira de temática gay: 1980-2009. In.: Camargo, F. P.; Silva, A. P. D. (Orgs.). Configurações homoeróticas na literatura. São Carlos: Claraluz, pp. 51-68, 2009.

FÉRREZ. "Terrorismo literário". In: FÉRREZ (Org.). Literatura marginal: talentos da escrita periférica. Rio de Janeiro: Agir, 2005. pp. 9-14.

FOUCAULT, Michel. O que é um autor. 7ed. Lisboa: Nova Veja, 2009.

GOTLIB, Nádia B. "A literatura feita por mulheres no Brasil". In.: BRANDÃO, Izabel; MUZART, Zahidè Lupinacci (Orgs). Refazendo nós: ensaios sobre mulher e literatura. Florianópolis: Ed. Mulheres, 2003.

HOUAISS, Antônio; VILLAR, Mauro de S. Minidicionário Houaiss da língua portuguesa. Rio de Janeiro: Objetiva, 2004.

KOTHE, Flávio. O cânone colonial. Brasília: Editora da Universidade de Brasília,1997.

. O cânone imperial. Brasília: Editora da Universidade de Brasília, 2000.

.O cânone republicano I. Brasília: Editora da Universidade de Brasília, 2003.

.O cânone republicano II. Brasília: Editora da Universidade de Brasília, 2004.

LUDMER, Josefina. Literaturas pós-autônomas. Sopro, v.20, pp. 1-4, Desterro, 2010.

MOISÉS, Massaud. A literatura brasileira através dos textos. São Paulo: Cultrix, 2007.

PICCHIO, Luciana Stegagno. História da literatura brasileira. Rio de Janeiro: Nova Aguilar,1997. 
RESENDE, Beatriz. Contemporâneos: Expressões da literatura brasileira no século XXI. Rio de Janeiro: Casa da Palavra: Biblioteca Nacional, 2008.

RONCARI, Luiz. Literatura Brasileira: dos primeiros cronistas aos últimos românticos. 2ed. São Paulo: Editora da Universidade de São Paulo/ EDUSP, 1995.

SILVA, Antonio de Pádua Dias da. Incursões teóricas sobre o conceito de litertura gay. In.: SocioPoética - v.1, n.7, 2010.

THOMÉ, Ricardo. Eros proibido: as ideologias em torno da questão homoerótica na literatura brasileira. Rio de Janeiro: Nova Razão Cultural Editora,2009.

VERÍSSIMO, José. História da literatura brasileira. São Paulo: Record, 1998.

Antonio de Pádua Dias da Silva é professor de teoria da literatura da Universidade Estadual da Paraíba. Doutor em Letras pela UFAL com estágio de pós-doutoramento pela UFRJ. É líder do grupo de pesquisa "Estudos de Representações de gênero e de sexualidades".

Carlos Eduardo Albuquerque Fernandes é professor de literatura da Universidade Federal Rural de Pernambuco, cursa doutorado em Letras pela UFPB; é membro dos grupos de pesquisa "Estudos de gênero na literatura e cultura: campos de tensão e produção", da UFPB e "Estudos de Representações de Gênero e de Sexualidades", da UEPB. 